\title{
Impactos Diferenciais da Pandemia de COVID-19 entre Imigrantes Internacionais Homens e Mulheres - Região Metropolitana de Belo Horizonte
}

\author{
Differential Impacts of the COVID-19 Pandemic Among International Immigrants by Gender \\ - Belo Horizonte Metropolitan Area
}

\author{
Felipe de Ávila Chaves Borges \\ Doutorando em Geografia - Tratamento da Informação Espacial, \\ Pontifícia Universidade Católica de Minas Gerais, Brasil \\ felipeacborges@gmail.com \\ Duval Magalhães Fernandes \\ Professor do Programa de Pós-Graduação em Geografia, \\ Pontifícia Universidade Católica de Minas Gerais, Brasil \\ duval@pucminas.br \\ Maria da Consolação Gomes de Castro \\ Professora Pontifícia Universidade Católica de Minas Gerais, Brasil \\ consolacastro@gmail
}

\begin{abstract}
Resumo
A humanidade atravessa sua pior crise sanitária e econômica em muito tempo. Seus impactos são sentidos nas dinâmicas econômicas e sociais e na saúde da população em todo planeta. Contudo, a forma como esses impactos afetam os diversos grupos são diferentes. Nesse sentido, este trabalho objetivou analisar os impactos socioeconômicos causados pela pandemia de Covid-19 entre homens e mulheres imigrantes internacionais na Região Metropolitana de Belo Horizonte. Apesar do desemprego ter aumentado entre homens e mulheres, as mulheres foram proporcionalmente mais afetadas. Isso fez com que imigrantes reduzissem suas despesas e, em muitos casos, sentissem sua própria existência ameaçada. Observou-se que as mulheres tiveram mais acesso ao auxílio emergencial que os homens e que estes últimos estão mais preocupados com questões de saúde e segurança alimentar que as mulheres, ao passo que preocupações de ordem econômica afligem mais as mulheres.
\end{abstract}

Palavras-chave: Pandemia, impactos socioeconômicos, imigrantes internacionais, homens, mulheres.

\begin{abstract}
Humanity is going through its worst health and economic crisis in a long time. Its impacts are felt in the economic and social dynamics and people's health across the world. However, the way these impacts affect different groups varies. In this sense, this study aimed to examine the socio-economic impacts caused by the Covid-19 pandemic among males and females international immigrants in the Belo Horizonte Metropolitan Area. Although unemployment has increased for men and women, women have been proportionally more affected. This made them cut their expenses and, in many cases, to feel their own existence threatened. It was observed that women had more access to emergency aid than men and that the latter are more concerned with health and food security issues, while economic issues are the major concerns for women.
\end{abstract}

Keywords: Pandemic, socio-economic impacts, international immigrants, men, women. 


\section{INTRODUÇÃO}

A pandemia causada pelo novo coronavírus Sars-Cov2 e sua doença Covid-19, modificou a vida cotidiana dos bilhões de habitantes no nosso planeta. Além de mais de um milhão de mortes e de dezenas de milhões de infectados (OMS, 2020), tem-se nos efeitos de contração econômica e perda de empregos uma situação potencialmente ainda mais prejudiciais a longo termo (KING et al., 2020). As medidas impostas para o controle da disseminação da doença, como o distanciamento social e o fechamento de certos setores da atividade econômica, escolas e outros serviços sociais, faz com que a atual crise econômica apresente diferentes nuances daquelas observadas em outros tempos.

A distribuição desigual entre homens e mulheres nos diferentes setores da economia, fez com que os homens fossem mais impactados pela perda de emprego em recessões anteriores nos EUA, já que os setores dominados por homens foram mais atingidos que aqueles dominados por mulheres (ALON et al., 2020). Entretanto, as especificidades da atual crise e resultados de pesquisas já realizadas indicam que as mulheres estão sendo mais impactadas desta vez (OIT, 2020).

De forma geral, as atividades mais impactadas são aquelas nas quais a demanda do setor é afetada pelas restrições impostas e as que sua natureza não permitem a realização de teletrabalho. Previsões feitas a partir dessas premissas apontavam para uma super-representação de mulheres nesses setores (ALON et al., 2020). Esses estudos ainda apontam para uma sobrecarga ainda maior sobre as mulheres no desempenho de atividades domésticas não remuneradas, como cuidado com os filhos ou idosos, o que pode repercutir negativamente nas atividades laborais remuneradas, seja diminuindo sua jornada de trabalho remunerada, seja impossibilitando de realizá-la. Além disso, as mulheres ocupam, no mais das vezes, trabalhos em setores informais, que oferecem baixa proteção social, o que facilita sua demissão ou impossibilita o acesso a licença remunerada, sobretudo em países em desenvolvimento (ONU, 2020) Esse cenário seria ainda pior levando em consideração que as mulheres têm maior probabilidade de trabalhar em atividades de tempo parcial ou em contratos temporários, as quais são menos assistidas por medidas de seguridade social (OIT, 2019). Por fim, Alon e outros (2020) alertam para o impacto a longo prazo dessa desigualdade, uma vez que as perdas de rendimento e emprego durante recessões possuem um efeito cumulativo maior sobre os ganhos futuros do quem outros momentos. A não reabertura de serviços escolares concomitantemente ao trabalho das mães ou diminuição da oferta desses serviços pode perpetuar por mais tempo essa condição (MALIK et al., 2020).

Analisando os impactos da pandemia entre pais e mães de famílias heterossexuais na Espanha, Farré e outros (2020) mostraram que as mulheres tinham maior probabilidade de ficarem desempregadas, obterem licença ou trabalharem em casa, assim como assumiam a maior parte dos cuidados com os filhos e tarefas domésticas. Já Adams-Prassl e outros (2020), utilizando amostras 
representativas da Alemanha, Reino Unido e Estados Unidos das Américas, encontraram maior probabilidade de redução de empregos e rendimento entre ocupações que não podem ser feitas em casa. Dentro dessas ocupações as mulheres e aqueles com menor escolaridade seriam os mais vulneráveis.

Na Inglaterra, Andrew e outros (2020) mostram que a contribuição de pais e mães nas tarefas domésticas aumentaram. Contudo, o maior aumento observado foi entre as mães, não só por elas terem sido mais acometidas pelas demissões, mas também aquelas que estão trabalhando de forma remunerada remotamente. Nesse último caso, observa-se que as mulheres acabam tendo menos condições de trabalharem initerruptamente por horas, diminuindo seu rendimento. Collins e outros (2020) chamam a atenção para o fato de as desigualdades de gênero estarem sendo exacerbadas pela pandemia nos Estados Unidos, fazendo com que mais mães sejam afetadas pelo desemprego e pela diminuição da jornada laboral, o que acarreta perdas econômicas a longo prazo.

O relatório de setembro da Organização Internacional do Trabalho (2020) "COVID-19 and the world of work. Sixth edition" mostra que em quase todos os países, inclusive no Brasil, as mulheres foram mais impactadas pelo desemprego causado pela atual. Muitos outros problemas causados pela pandemia estão associados à desigualdade de gênero, como o aumento da violência doméstica (BRÜLHART; LALIVE, 2020) e problemas relacionados à saúde mental (ETHERIDGE; SPANTIG, 2020). Contudo, as desigualdades com que a pandemia atinge diferente grupos não se restringe às questões de gênero. Imigrantes internacionais também devem ser impactados sobremaneira pelas crises geradas pela pandemia.

O fechamento de fronteiras torna ainda mais difícil a saída de pessoas de países em graves crises humanitárias, colocando em risco pessoas perseguidas em seus países de origem. Os assentamentos e abrigos para refugiados, de forma geral, são superlotados e não oferecem condições sanitárias adequadas, o que inviabiliza a adoção das medidas necessárias para contenção da Covid19 (KLUGE et al., 2020).

Nos Estados Unidos, Gelatt (2020) e Clark e outras (2020) alertam para o impacto desproporcional nas comunidades imigrantes do país. Dentre outros fatores, a maior presença de imigrantes em trabalhos essenciais, a dificuldade de acesso desses a tratamento de saúde e maior índice de comorbidades os tornam mais vulneráveis a contração e desenvolvimento das formas mais graves das doenças. Além disso, a dificuldade dos imigrantes de serem assistidos por programas sociais de combate ao desemprego e insegurança alimentar, põe esse grupo em maior vulnerabilidade socioeconômica, repercutindo negativamente na comunidade imigrante estadunidense e nas comunidades assistidas por remessas enviadas pelos imigrantes.

No Brasil, Fernandes, Baeninger e Demétrio (2020), em estudo sobre os impactos da pandemia sobre os imigrantes internacionais, revelaram que de 2475 imigrantes entrevistados, apenas 
1184 estavam trabalhando antes da pandemia. Os dados indicam que cerca de 55\% deles trabalhavam no setor de serviços e comércio, fortemente impactados pela pandemia. Após o início da pandemia, apenas 689 dos imigrantes afirmaram estar trabalhando, indicando que os efeitos econômicos da pandemia se manifestavam de forma avassaladora sobre aquela população. Analisando os dados do estado de Minas Gerais, Fernandes et al. (2020) indicaram a informalidade como maior fator explicativo para a perda de emprego entre imigrantes durante o período de pandemia. Contudo, não foram feitas análises sobre os impactos diferenciais experimentados entre homens e mulheres imigrantes.

Visando contribuir com o debate acerca dos impactos da pandemia sobre os imigrantes internacionais e a desigualdade de gênero que possivelmente afeta essa comunidade, este trabalho tem como objetivo analisar os impactos diferenciais causados pela pandemia e suas repercussões de ordem social e econômica entre homens e mulheres imigrantes internacionais na Região Metropolitana de Belo Horizonte (RMBH). A identificação e compreensão dos impactos que a crise da pandemia de Covid-19 causa em diferentes subgrupos de imigrantes é essencial para guiar políticas públicas e ações de organizações da sociedade civil mais efetivas e direcionadas.

\section{METODOLOGIA}

Os dados utilizados neste trabalho foram retirados da pesquisa "Impactos da Pandemia de Covid-19 nas Migrações Internacionais", realizada pelos grupos de pesquisa "Grupo Interdisciplinar de Pesquisa e Extensão - Direitos Sociais e Migração (GIPE) coordenado pela professor Maria da Consolação Gomes de Castro, Grupo de Estudos de Distribuição da População (GEDEP), coordenado pelo professor Duval Fernandes, ambos da PUC Minas, e pelo Observatório das Migrações em São Paulo - Núcleo de Estudos da População Elza Berquó da Universidade Estadual de Campinas (NEPO/UNICMP), sob a tutela da professora Rosana Baeninger.

Contando com o apoio de 15 instituições de ensino superior e dez organizações da sociedade civil, órgãos governamentais e organizações internacionais, a pesquisa foi feita de forma remota, consonante à realidade imposta pela pandemia. Foi disponibilizado entre 12 de maio e 6 de julho, um questionário em seis idiomas diferentes via internet (plataforma Google Forms) com cerca de 60 questões divididas em quatro seções ${ }^{1}$ : caracterização geral dos respondentes, aspectos da imigração para o Brasil, inserção laboral na pandemia de Covid-19 e direitos sociais e pandemia. A aplicação dos questionários se deu por meio de livre acesso ao endereço eletrônico do questionário e por agentes intermediários e instituições que realizaram a entrevista, sobretudo por meio do aplicativo de

\footnotetext{
${ }^{1}$ Para maiores detalhes sobre os procedimentos metodológicos adotados na coleta dos dados e acesso a todas as questões do questionário ver Fernandes et al. (2020) e Baeninger e Fernandes (2020).
} 
mensagens WhatsApp e foram impulsionadas por imigrantes-mediadores e organizações de acolhimento a imigrantes que articularam a divulgação da pesquisa entre a comunidade imigrante. Assim, a pesquisa utilizou uma rede intencional e deve ser encarada como uma pesquisa qualitativa sem definição amostral (BAENINGER; FERNANDES, 2020).

Por meio do programa IBM SPSS Statistics 23 os dados da pesquisa foram filtrados de modo a retornar somente aqueles referentes a moradores de municípios da RMBH. Posteriormente, separouse o banco de dados em dois: um relativo aos respondentes homens e outro às respondentes mulheres. Para ambos os grupos foram calculadas estatísticas descritivas e tabelas de referência cruzada. Enquanto as estatísticas descritivas buscaram traçar o perfil da comunidade pesquisada e medir o impacto da pandemia nesse grupo sobre aspectos laborais e sociais, as tabelas de referência cruzadas serviram ao objetivo de buscar conexão entre esses diferentes aspectos. Os resultados obtidos foram organizados em tabelas e gráficos, elaborados por meio do software Microsoft Excel, e em um cartograma feito no software ArcGis 10.5.

Embora a pesquisa tenha alcançado 99 respondentes na $\mathrm{RMBH}$, as particularidades de cada questão, que podem ou não se aplicar a todos os participantes da pesquisa, faz com que a base de cálculo das estatísticas descritivas se difira entre elas. Por outro lado, como o respondente poderia se furtar a responder algumas questões, foi preciso desconsiderar casos em que todas as respostas necessárias para o estabelecimento de relações entre diferentes perguntas não foram apresentadas pelo respondente. Isso foi particularmente utilizado na busca por determinantes da perda de empregos pelos imigrantes homens e mulheres durante a pandemia. A tabela 1 apresenta a quantidade de respostas totais, de homens e de mulheres e a composição do grupo avaliado para cada um dos temas abordados nessa pesquisa.

Tabela 1 - Quantidade de respostas aplicáveis aos temas abordados na pesquisa e sua composição.

\begin{tabular}{|c|c|c|c|c|}
\hline Tema & $\begin{array}{l}\text { Resposta } \\
\text { s } \\
\text { avaliadas }\end{array}$ & $\begin{array}{l}\text { Respostas } \\
\text { avaliadas } \\
\text { Homens }\end{array}$ & $\begin{array}{l}\text { Respostas } \\
\text { avaliadas } \\
\text { Mulheres }\end{array}$ & Composição das respostas avaliadas \\
\hline $\begin{array}{l}\text { Município de residência, } \\
\text { nacionalidade, faixa etária, } \\
\text { estado civil e cor }\end{array}$ & 99 & 51 & 48 & Todos os participantes \\
\hline Nacionalidade do cônjuge & 46 & 26 & 20 & Participantes casados ou em união estável \\
\hline País onde moram os filhos & 55 & 29 & 26 & Participantes com filhos \\
\hline $\begin{array}{l}\text { Arranjo domiciliar e condição de } \\
\text { moradia, status migratório }\end{array}$ & 99 & 51 & 48 & Todos os participantes \\
\hline $\begin{array}{l}\text { Ocupação antes e durante a } \\
\text { pandemia }\end{array}$ & 86 & 43 & 43 & $\begin{array}{c}\text { Participantes que não indicaram idade } \\
\text { inferior a } 16 \text { anos e responderam se estavam } \\
\text { ou não trabalhando antes da pandemia e } \\
\text { após o seu início }\end{array}$ \\
\hline $\begin{array}{l}\text { Informações laborais: situação } \\
\text { trabalhista e setor de ocupação }\end{array}$ & 50 & 28 & 22 & $\begin{array}{c}\text { Participantes que não indicaram idade } \\
\text { inferior a } 16 \text { anos e responderam que } \\
\text { estavam trabalhando antes da pandemia e } \\
\text { que estavam ou não trabalhando após o seu } \\
\text { início }\end{array}$ \\
\hline
\end{tabular}


Impacto da pandemia no trabalho atual

31

Relação entre despesa e rendimento, envio de remessas

Conhecimento e busca de informações sobre direitos sociais e acesso a eles

Onde buscou informações

Inscrição em programas sociais

Motivo de não inscrição no auxílio emergencial

Acesso ao SUS, contato com a Covid-19, dificuldade em lidar com o isolamento social, se pede ajuda a organizações de apoio aos migrantes

Tipo de ajuda pedida para organizações de apoio aos imigrantes

A quem recorre em caso de necessidade, medidas tomadas em função da pandemia, principais medos e preocupações e planos migratórios

99

50

99

27

99 $\begin{array}{lll}96 & 50 & 46\end{array}$

$\begin{array}{lll}99 & 51 \quad 48\end{array}$

$\begin{array}{lll}36 & 18 & 18\end{array}$

51

48

29

21

51

48

11

16

Participantes que responderam pedir ajuda para organizações de apoio aos imigrantes 51 48

Participantes que estavam empregados no momento da entrevista

Participantes que não indicaram idade inferior a 16 anos

Todos os participantes

Participantes que buscaram informações sobre como acessar seus direitos sociais

Todos os participantes

Participantes que responderam não estarem inscritos no programa "Auxílio

Emergencial" do Governo Federal

Todos os participantes

Fonte: Dados da pesquisa, 2020

\section{RESULTADOS E DISCUSSÃO}

A pesquisa alcançou 99 respondentes na $\mathrm{RMBH}$, com destaque para Belo Horizonte (80) e Contagem (10). A distribuição por sexo foi equilibrada, sendo entrevistados 51 homens e 48 mulheres imigrantes. Nos municípios de Betim, Nova Lima e Ribeirão das Neves só se entrevistou mulheres, em Santa Luzia um homem e em Belo Horizonte, Contagem e Esmeraldas observou-se uma distribuição regular entre ambos sexos. Não foram respondidos questionários por imigrantes residentes dos demais município da $\mathrm{RMBH}$. O mapa e a tabela seguintes indicam a distribuição espacial dos respondentes. 


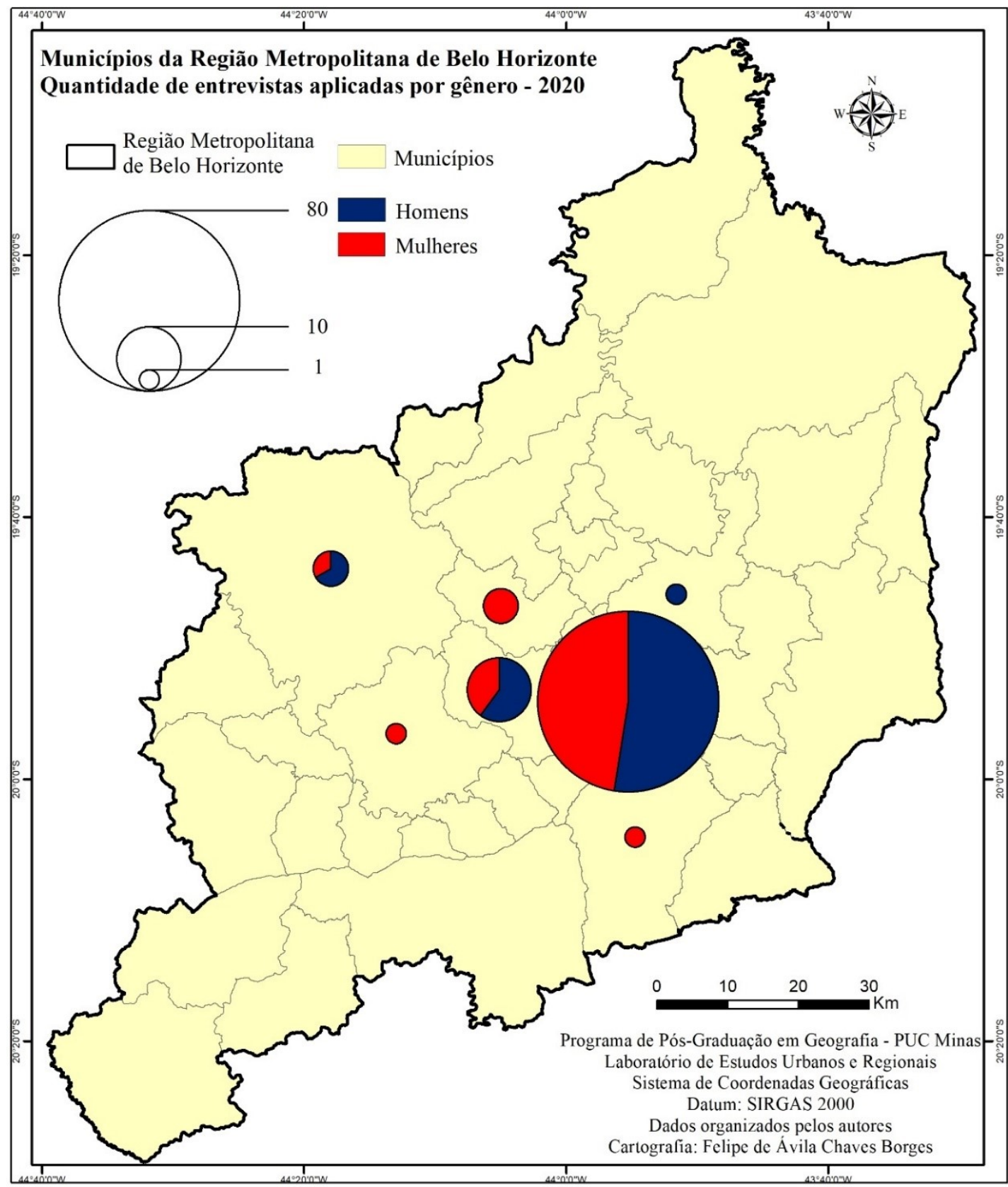

Figura 1 - Imigrantes internacionais participantes da pesquisa por município de residência e gênero. Região Metropolitana de Belo Horizonte, 2020 (n=99).

Fonte: Dados da pesquisa, 2020.

Tabela 2 - Imigrantes internacionais participantes da pesquisa por município de residência. Região Metropolitana de Belo Horizonte, $2020(\mathrm{n}=99, \mathrm{~h}=51, \mathrm{~m}=48)$.

\begin{tabular}{ccc}
\hline Município & Homens & Mulheres \\
\hline Belo Horizonte & 42 & 38 \\
Betim & 0 & 1 \\
Contagem & 6 & 4 \\
Esmeraldas & 2 & 1 \\
Nova Lima & 0 & 1 \\
Ribeirão das Neves & 0 & 3 \\
Santa Luzia & 1 & 0 \\
Total & $\mathbf{5 1}$ & $\mathbf{4 8}$ \\
\hline
\end{tabular}

Fonte: Dados da pesquisa, 2020. 
Dentre os respondentes observa-se predomínio de venezuelanos (33) e haitianos (33), tendo em vista o grande fluxo de migrantes desses dois países para o Brasil na última década. Além de venezuelanos e haitianos, observa-se respondentes de outras 16 nacionalidades, com destaque para Gana (sete), Colômbia (quatro) e Chile e Peru (três cada) e um apátrida, como mostra a tabela a seguir.

Tabela 3 - Imigrantes internacionais participantes da pesquisa por nacionalidade e gênero. Região Metropolitana de Belo Horizonte, $2020(\mathrm{n}=99, \mathrm{~h}=51, \mathrm{~m}=48)$.

\begin{tabular}{cccccccc}
\hline Nacionalidade & Homens & Mulheres & Total & Nacionalidade & Homens & Mulheres & Total \\
\hline Apátrida & 0 & 1 & 1 & Itália & 1 & 0 & 1 \\
Cabo Verde & 0 & 1 & 1 & Marrocos & 0 & 2 & 2 \\
Chile & 0 & 3 & 3 & Moçambique & 1 & 0 & 1 \\
Colômbia & 3 & 1 & 4 & Nicarágua & 1 & 1 & 2 \\
Congo RDC & 2 & 0 & 2 & Peru & 1 & 2 & 3 \\
Cuba & 0 & 1 & 1 & Guiné Bissau & 1 & 0 & 1 \\
Equador & 1 & 0 & 1 & Síria & 1 & 0 & 1 \\
Gana & 6 & 1 & 7 & Timor Leste & 0 & 1 & 1 \\
Haiti & 24 & 9 & 33 & Venezuela & 9 & 24 & 33 \\
Índia & 0 & 1 & 1 & Total & 51 & 48 & 99 \\
\hline
\end{tabular}

Fonte: Dados da pesquisa, 2020.

A figura 2 traz uma série de características dos respondentes. Em relação a idade, percebese que há forte concentração da amostra em adultos, poucas crianças e adolescentes, que são na maior parte mulheres, e nenhum idoso acima de 65 anos em ambos os gêneros. Entre os homens observa-se maior presença de negros, mas com significativo número de brancos e pardos. Já entre as mulheres há maior homogeneidade na distribuição entre pardas, negras e brancas. Em relação ao estado civil $51 \%$ dos homens eram casados e $45 \%$ solteiros, frente a $52 \%$ de mulheres solteiras e $42 \%$ de mulheres casadas. A grande maioria dos homens casados tem como companheiras pessoas da mesma nacionalidade, tendo apenas um indicado ser companheiro de uma brasileira e outro não respondido. Já das 20 mulheres casadas, 16 (80\%) indicaram cônjuge da mesma nacionalidade, duas (10\%) brasileiros e outras duas de outras nacionalidades. Dentre os homens, 29 (57\%) responderam terem filhos, ao passo que esse número entre as mulheres é inferior: 22 (46\%). Contudo, as mulheres parecem estar mais vinculadas aos seus filhos, já que, entre as mães, quase $70 \%$ afirmaram que todos os filhos vivem no país, enquanto esse número entre os pais é inferior a $50 \%$. 


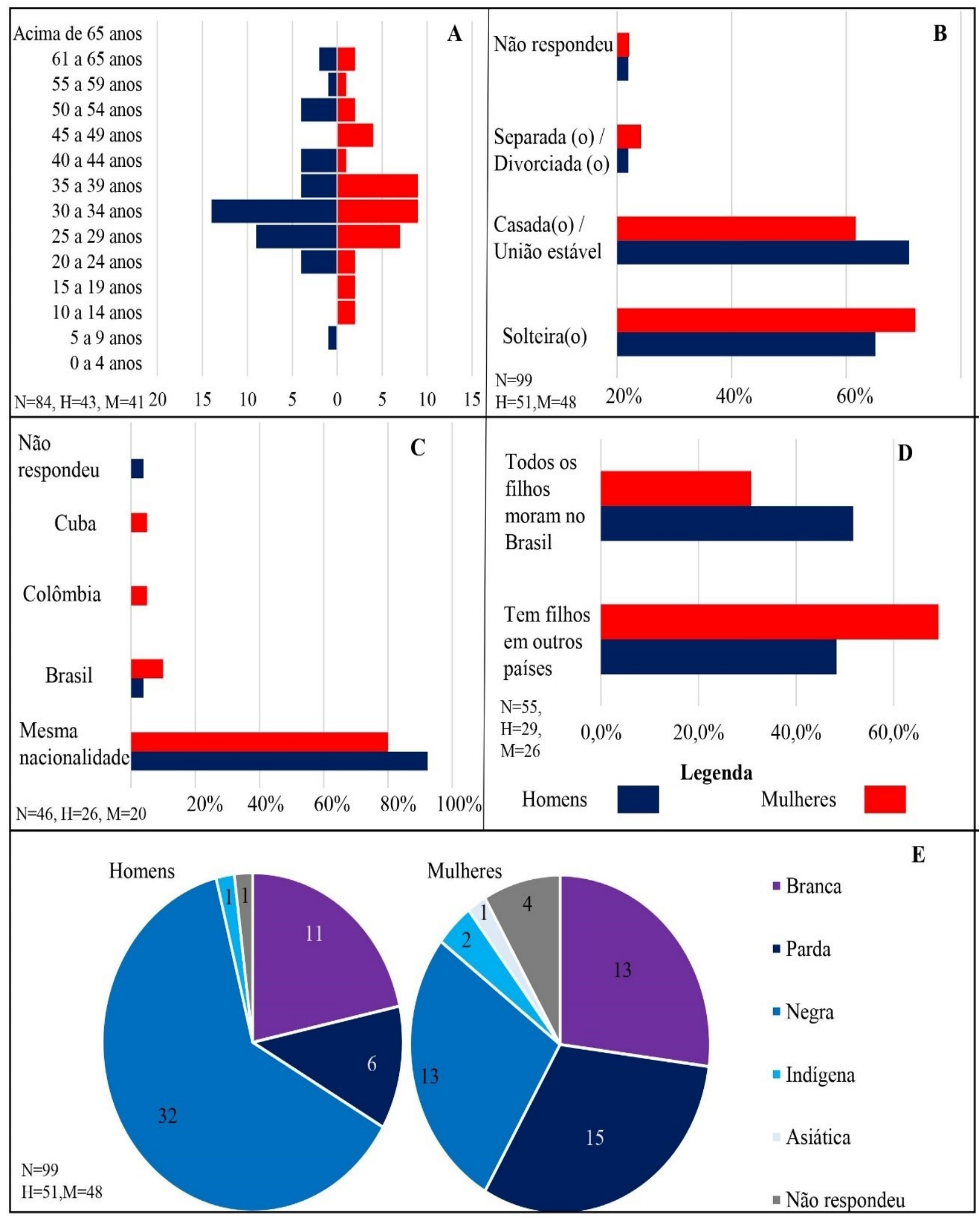

Figura 2 - Caracterização dos imigrantes entrevistados por gênero: faixa etária (A), estado civil (B), nacionalidade do cônjuge (C), país de residência dos filhos (D) e cor (E). Região Metropolitana de Belo Horizonte, 2020.

Fonte: Dados da pesquisa, 2020.

Como mostra a tabela 4 , a maior parte dos homens $(52.9$ a $56,8 \%)$ e das mulheres $(62,6$ a $66,8 \%$ ) imigrantes vivem sozinho ou com a família, o que, em certa medida, torna mais fácil seguir as medidas de isolamento social. Contudo, além de ser alta a proporção daqueles que vivem com 
terceiros (cerca de $45 \%$ dos homens e $35 \%$ das mulheres), a grande maioria dos imigrantes, tanto homens $(89,2 \%)$ quanto mulheres $(85,5 \%)$, vivem de aluguel ou em domicílio fornecido pelos empregadores, o que os colocam em posição vulnerável em meio à forte contração econômica e aumento do desemprego.

Tabela 4 - Imigrantes internacionais participantes da pesquisa segundo moradia e arranjo domiciliar por gênero. Região Metropolitana de Belo Horizonte, 2020 ( $n=99, \mathrm{~h}=51, \mathrm{~m}=49)$.

\begin{tabular}{lrr}
\hline \multicolumn{1}{c}{ Moradia e Arranjo Domiciliar } & Homens & Mulheres \\
\hline Vivo sozinho/a (ou com o companheiro/ cônjuge/filhos) em casa/apt alugada & $49 \%$ & $56,3 \%$ \\
Vivo sozinho/a (ou com o companheiro/ cônjuge/filhos) em casa /apt própria & $3,9 \%$ & $6,3 \%$ \\
Vivo em casa/apt de familiares/amigos & $3,9 \%$ & $4,2 \%$ \\
Vivo com uma ou mais pessoas, partilho casa/apt. alugada & $29,4 \%$ & $22,9 \%$ \\
Vivo com uma ou mais pessoas, partilho um quarto alugado, numa residência particular & $5,9 \%$ & $4,2 \%$ \\
Vivo em casa /apartamento fornecida pelo empregador & $5,9 \%$ & $2,1 \%$ \\
Não respondeu & $2 \%$ & $4,2 \%$ \\
Total & $100 \%$ & $100 \%$ \\
\hline
\end{tabular}

Fonte: Dados da pesquisa, 2020

O status migratório de um imigrante pode facilitar o acesso a documentação necessária para programas sociais do governo brasileiro e o mercado de trabalho formal. Nesse sentido, foi perguntado qual o atual status migratório dos respondentes (tabela 5). A maior parte dos homens e mulheres possuem autorização de residência temporária ou permanente no país. A discrepância entre os dois grupos está entre aqueles que possuem visto humanitário ${ }^{2}$, maior parte homens, e os refugiados, maior parte mulheres. Tal diferença reside no fato do grande número de homens haitianos e de mulheres venezuelanas. De toda forma, a exceção de uma mulher que declarou possuir visto de turista, os imigrantes que responderam à essa questão são legalmente aptos a acessarem os programas e benefícios sociais no país.

Uma das mais severas consequências da pandemia é o desemprego. Considerando que, de forma geral, os imigrantes se encontram em posição econômica mais vulnerável que aqueles naturais do país, é de se esperar que esses sejam fortemente impactados no que se refere às atividades laborais. Da mesma forma, a inserção e o tratamento diferencial que o mercado de trabalho brasileiro dá a homens e mulheres pode impactar de forma diferente esses dois grupos. Assim, analisa-se as respostas de 43 imigrantes homens e 43 imigrantes mulheres. Os demais entrevistados não responderam

\footnotetext{
${ }^{2}$ A partir de 2010 grupos de haitianos passaram a migrar para o Brasil, fugindo das graves crises econômica, social, política e ambiental que o país atravessava (FERNANDES; FARIA, 2017). Por meio da Portaria Interministerial $\mathrm{n}^{\circ} 10$, de 6 de abril de 2018, o Brasil passou a facilitar a entrada de nacionais haitianos e apátridas residentes no Haiti, dando a eles tratamento prioritário para fins humanitários. O visto humanitário passou a ser emitido pela Embaixada do Brasil em Porto Príncipe e conceder residência temporária de dois anos no Brasil, passível de transformação em residência por prazo indeterminado ao final do primeiro período (BRASIL, 2018). Em 2019 as diretrizes para a concessão desse tipo de visto foram atualizadas pela Portaria Interministerial nº 12, de 20 de dezembro de 2019 (BRASIL, 2019).
} 
algumas questões sobre sua atividade laboral ou indicaram idade inferior a 16 anos, sendo, portanto, excluídos da análise.

Tabela 5 - Imigrantes internacionais participantes da pesquisa segundo status migratório e gênero. Região Metropolitana de Belo Horizonte, $2020(\mathrm{n}=99, \mathrm{~h}=51, \mathrm{~m}=49)$.

\begin{tabular}{lcc}
\hline \multicolumn{1}{c}{ Status migratório } & Homens & Mulheres \\
\hline Visto de turista de 90 dias que recebi ao entrar no Brasil & $0 \%$ & $2,1 \%$ \\
Visto humanitário recebido em meu país ou ao entrar no Brasil & $11,8 \%$ & $2,1 \%$ \\
Autorização de residência temporária ou permanente. & $68,6 \%$ & $77,1 \%$ \\
Solicitação de refúgio ao entrar no Brasil e aguardo a resposta do Ministério da Justiça & $5,9 \%$ & $4,2 \%$ \\
Refugiado & $3,9 \%$ & $12,5 \%$ \\
Naturalizado Brasileiro & $5,9 \%$ & $0 \%$ \\
Não respondeu & $3,9 \%$ & $2,1 \%$ \\
\cline { 2 - 3 } Total & $100 \%$ & $100 \%$ \\
\hline
\end{tabular}

Fonte: Dados da pesquisa, 2020.

Antes do início da pandemia $65 \%$ dos homens e 50,1\% das mulheres estavam empregados. Considerando o grande grupo ocupacional daqueles que estavam empregados há forte participação dos trabalhadores dos serviços, vendedores do comércio em lojas e mercados, que representam 50\% dos homens e $41 \%$ das mulheres empregadas antes da pandemia. Também importante são os profissionais das ciências e das artes, que correspondiam a 21,4\% e 22,7\% dos homens e mulheres empregados respectivamente. Técnicos do nível médio eram 7,1\% entre os homens e 13,6\% entre as mulheres. Enquanto apenas uma mulher (4,5\%) se enquadrava em serviços administrativos, apenas homens eram trabalhadores da produção de bens e serviços industriais $(10,7 \%)$. Três homens e quatro mulheres não indicaram sua ocupação, apesar de afirmarem estar trabalhando.

Ainda que muitas vezes em empregos de baixa remuneração, é possível perceber que grande parte daqueles que trabalhavam antes do início da pandemia o fazia no mercado formal (tabela 6). Entre os homens 75\% tinham carteira assinada e 7,1\% eram autônomos formais, frente a 63,6\% e $13,6 \%$ dentre as mulheres respectivamente. Os homens que trabalhavam como empregados e sem carteira assinada correspondiam a 7,4\% do total, similar as mulheres nessa situação: 9,1\%. Já as mulheres trabalhavam mais como autônomas informais: $13,6 \%$ contra apenas 3,6\% dos homens.

No que se refere ao setor de trabalho de homens e mulheres imigrantes, observa-se que o que mais os empregavam era o de comércio, alojamento e restauração, transportes e estética. Também tinham forte participação em ambos os sexos os serviços pessoais e atividades domésticas e serviços às empresas e atividades financeiras. Já os setores agrícola, industrial e de educação são mais representativos no universo dos homens, ao passo que o artesanato era mais marcante para as mulheres. O número de trabalhadores por sexo e setor da economia pode ser viso na tabela 7. 
Tabela 6 - Imigrantes internacionais participantes da pesquisa empregados antes da pandemia de Covid-19 por condição no trabalho e gênero. Região Metropolitana de Belo Horizonte, 2020 (n=50, h=28, m=22).

\begin{tabular}{lcccc}
\hline \multicolumn{1}{c}{ Situação trabalhista } & \multicolumn{2}{c}{ Homens } & \multicolumn{2}{c}{ Mulheres } \\
\cline { 2 - 5 } & Número & \% & Número & \% \\
\hline Trabalhava como autônomo (microempresa, pessoa jurídica ou MEI) & 2 & 7,1 & 3 & 13,6 \\
Trabalhava com carteira assinada & 21 & 75 & 14 & 63,6 \\
Trabalhava sem carteira assinada & 2 & 7,4 & 2 & 9,1 \\
Trabalhava como voluntário & 2 & 7,1 & 0 & 0 \\
Autônomo informal & 1 & 3,6 & 3 & 13,6 \\
\hline
\end{tabular}

Fonte: Dados da pesquisa, 2020.

Tabela 7 - Imigrantes internacionais participantes da pesquisa empregados antes da pandemia de Covid-19 por setor da economia e gênero. Região Metropolitana de Belo Horizonte, 2020 ( $n=50, h=28, m=22)$.

\begin{tabular}{lcccc}
\hline \multicolumn{1}{c}{ Setor } & \multicolumn{2}{c}{ Homens } & \multicolumn{2}{c}{ Mulheres } \\
\cline { 2 - 5 } & Número & \% & Número & \% \\
\hline Agricultura & 1 & 3,6 & 0 & 0,0 \\
Indústria & 5 & 17,9 & 2 & 9,1 \\
Comércio, alojamento e restauração, transportes, estética & 5 & 17,9 & 6 & 27,3 \\
Serviços às empresas, atividades financeiras & 4 & 14,3 & 4 & 18,2 \\
Educação & 5 & 17,9 & 2 & 9,1 \\
Saúde & 2 & 7,1 & 1 & 4,5 \\
Serviços pessoais, atividades domésticas & 5 & 17,9 & 4 & 18,2 \\
Artesanato & 1 & 3,6 & 3 & 13,6 \\
\hline
\end{tabular}

Fonte: Dados da pesquisa, 2020.

Se antes do início da pandemia já era alta a proporção de desempregados, após o início esse quadro se agravou (tabela 8). Dos 28 homens ocupados, 10 perderam sua atividade, saltando a proporção de desempregados de $34,9 \%$ para $58,1 \%$. Se antes eram vinte e duas as mulheres ocupadas, depois do início da pandemia o número caiu para 13 , modificando a taxa de desocupadas de $48,8 \%$ para 69,8\%. Das 13 mulheres que se encontram trabalhando depois do início da pandemia, três começaram a atividade laboral durante o período de pandemia e outra trocou de emprego durante a pandemia.

Tabela 8 - Imigrantes internacionais participantes da pesquisa segundo inserção laboral antes e depois do início da pandemia de Covid-19 por gênero. Região Metropolitana de Belo Horizonte, 2020 ( $\mathrm{n}=86, \mathrm{~h}=43$, m=43).

\begin{tabular}{|c|c|c|c|c|c|c|c|c|}
\hline \multirow{3}{*}{ Inserção Laboral } & \multicolumn{4}{|c|}{ Homens } & \multicolumn{4}{|c|}{ Mulheres } \\
\hline & \multicolumn{2}{|c|}{ Antes da pandemia } & \multicolumn{2}{|c|}{$\begin{array}{c}\text { Depois do início da } \\
\text { pandemia }\end{array}$} & \multicolumn{2}{|c|}{ Antes da pandemia } & \multicolumn{2}{|c|}{$\begin{array}{l}\text { Depois do início da } \\
\text { pandemia }\end{array}$} \\
\hline & Número & $\%$ & Número & $\%$ & Número & $\%$ & Número & $\%$ \\
\hline Estava trabalhando & 28 & 65,1 & 18 & 41,9 & 22 & 51,2 & 10 & 23,3 \\
\hline Não estava trabalhando & 15 & 34,9 & 25 & 58,1 & 21 & 48,8 & 30 & 69,8 \\
\hline $\begin{array}{l}\text { Começou a trabalhar depois } \\
\text { da pandemia }\end{array}$ & \multicolumn{2}{|c|}{$\mathrm{X}$} & 0 & 0 & \multicolumn{2}{|c|}{$\mathrm{X}$} & 3 & 7 \\
\hline
\end{tabular}

Fonte: Dados da pesquisa, 2020. 
Desta forma, se levarmos em consideração apenas aqueles que já estavam trabalhando antes da pandemia, temos que 35,7\% dos homens deixaram de ter atividade laboral, enquanto essa proporção entre as mulheres foi de 54,5\% (desconsiderando a que trocou de emprego), indicando uma maior vulnerabilidade das mulheres em se manter no trabalho durante o período pandêmico.

Buscando melhor compreender essa dinâmica, cruzou-se os dados daqueles que se mantiveram, trocaram ou perderam seu emprego com a situação trabalhista anterior à pandemia (tabela 9). A partir desses cruzamentos percebe-se que a informalidade é a explicação para grande parte da perda de empregos e ajuda a explicar a diferenciação do impacto da pandemia no emprego de homens e mulheres. Todos os trabalhadores informais (empregados sem carteira assinada e autônomos informais) perderam sua atividade, tanto homens quanto mulheres. Além disso, as mulheres autônomas formais parecem ter sido mais atingidas que os homens, apesar de haver poucos casos para ilustrar essa situação. Por fim, dentre aqueles que possuíam carteira assinada houve o maior nível de retenção no emprego. Entretanto, esse alto nível de manutenção de empregos é maior para os homens (76\%) que para as mulheres (57\% mantiveram no emprego e 7\% trocou de emprego). Desta forma, a maior proporção de mulheres na informalidade é capaz de explicar em parte o maior impacto da pandemia em seus empregos, mas a diferenciação de retenção no trabalho entre os trabalhadores formais homens e mulheres indicam que a informalidade não é a única explicação.

Tabela 9 - Imigrantes internacionais participantes da pesquisa empregados antes da pandemia de Covid-19 por condição no trabalho e gênero. Região Metropolitana de Belo Horizonte, 2020 (n=50, h=28, m=22).

\begin{tabular}{lcccccc}
\hline \multicolumn{1}{c}{ Situação trabalhista } & $\begin{array}{c}\text { Manteve o } \\
\text { Emprego }\end{array}$ & $\begin{array}{c}\text { Trocou de } \\
\text { Emprego }\end{array}$ & $\begin{array}{c}\text { Perdeu o } \\
\text { emprego }\end{array}$ & $\begin{array}{c}\text { Manteve o } \\
\text { Emprego }\end{array}$ & $\begin{array}{c}\text { Mulheres } \\
\text { Emprego }\end{array}$ & $\begin{array}{c}\text { Perdeu o } \\
\text { emprego }\end{array}$ \\
\hline $\begin{array}{l}\text { Trabalhava como autônomo } \\
\text { (microempresa, pessoa jurídica ou MEI) }\end{array}$ & $50 \%(1)$ & $0 \%$ & $50 \%(1)$ & $33 \%(1)$ & $0 \%$ & $67 \%(2)$ \\
Trabalhava com carteira assinada & $76 \%(16)$ & $0 \%$ & $24 \%(5)$ & $57 \%(8)$ & $7 \%(1)$ & $36 \%(5)$ \\
Trabalhava sem carteira assinada & $0 \%$ & $0 \%$ & $100 \%(2)$ & $0 \%$ & $0 \%$ & $100 \%(2)$ \\
Trabalha como voluntário & $50 \%(1)$ & $0 \%$ & $50 \%(1)$ & $X$ & $X$ & $X$ \\
Autônomo informal & $0 \%$ & $0 \%$ & $100 \%(1)$ & $0 \%$ & $0 \%$ & $100 \%(3)$ \\
\hline
\end{tabular}

Fonte: Dados da pesquisa, 2020.

Tendo em vista as diferentes restrições de funcionamento dos diversos setores da economia durante o período de pandemia, é possível que a distribuição de homens e mulheres nos diferentes setores influencie de maneira desigual no aumento do desemprego desses gêneros. Nos setores de saúde e serviços às empresas e atividades financeiras observou-se alta taxa de manutenção de empregos para os migrantes de ambos os sexos, $100 \%$ entre homens e $75 \%$ entre mulheres (tabela $10)$.

No setor de indústrias os homens, que eram maioria, foram mais impactados, haja vista que $80 \%$ foram demitidos, ao passo que as duas mulheres que trabalhavam no setor mantiveram seus 
empregos. Já no artesanato o único representante homem perdeu o emprego, assim como aconteceu com duas das três mulheres que trabalhavam no setor. Embora também impactados no setor de educação, os homens conseguiram se manter em 40\% das vagas, enquanto nenhuma mulher o conseguiu. Também foram as mulheres as mais impactadas no setor de serviços pessoais e atividades domésticas, tendo $50 \%$ delas perdido o emprego frente $20 \%$ dos homens.

Contudo, o que mais chama atenção é o setor de comércio, alojamento e restauração, transportes e estética. Setor que mais empregava as mulheres e os homens, todos os homens se mantiveram no emprego, mas a grande maioria das mulheres não (83\%). Assim, embora os homens estivessem distribuídos de forma mais uniforme nos diferentes setores, o que poderia atenuar os impactos do fechamento desigual da economia durante a pandemia, observa-se que dentro do mais importante setor para o emprego das mulheres imigrantes há uma diferença enorme na manutenção dos empregos entre os dois gêneros. Ressalta-se, ainda, que a formalidade não é capaz de explicar essa diferença no setor de comércio, uma vez que cinco das seis mulheres trabalhavam formalmente neste setor (quatro de carteira assinada e uma como microempresa, pessoa jurídica ou MEI).

Tabela 10 - Imigrantes internacionais participantes da pesquisa empregados antes da pandemia de Covid-19 por setor da economia e gênero. Região Metropolitana de Belo Horizonte, 2020 ( $\mathrm{n}=50, \mathrm{~h}=28, \mathrm{~m}=22)$.

\begin{tabular}{|c|c|c|c|c|c|c|}
\hline \multirow[b]{2}{*}{ Setor } & \multicolumn{3}{|c|}{ Homens } & \multicolumn{3}{|c|}{ Mulheres } \\
\hline & $\begin{array}{l}\text { Manteve o } \\
\text { Emprego }\end{array}$ & $\begin{array}{l}\text { Trocou de } \\
\text { Emprego }\end{array}$ & $\begin{array}{l}\text { Perdeu o } \\
\text { emprego }\end{array}$ & $\begin{array}{l}\text { Manteve o } \\
\text { Emprego }\end{array}$ & $\begin{array}{l}\text { Trocou de } \\
\text { Emprego }\end{array}$ & $\begin{array}{l}\text { Perdeu o } \\
\text { emprego }\end{array}$ \\
\hline Agricultura & $100 \%(1)$ & $0 \%$ & $0 \%$ & $\mathrm{X}$ & $\mathrm{X}$ & $\mathrm{X}$ \\
\hline Indústria & $20 \%(1)$ & $0 \%$ & $80 \%(4)$ & $100 \%(2)$ & $0 \%$ & $0 \%$ \\
\hline $\begin{array}{l}\text { Comércio, alojamento e restauração, } \\
\text { transportes, estética }\end{array}$ & $100 \%(5)$ & $0 \%$ & $0 \%$ & $16,7 \%(1)$ & $0 \%$ & $83 \%(5)$ \\
\hline $\begin{array}{l}\text { Serviços às empresas, atividades } \\
\text { financeiras }\end{array}$ & $75 \%(3)$ & $0 \%$ & $25 \%(1)$ & $75 \%(3)$ & $0 \%$ & $25 \%(1)$ \\
\hline Educação & $40 \%(2)$ & $0 \%$ & $60 \%(3)$ & $0 \%$ & $0 \%$ & $100 \%(2 \%)$ \\
\hline Saúde & $100 \%(2)$ & $0 \%$ & $0 \%$ & $0 \%$ & $100 \%(1)$ & $0 \%$ \\
\hline $\begin{array}{l}\text { Serviços pessoais, atividades } \\
\text { domésticas }\end{array}$ & $80 \%(4)$ & $0 \%$ & $20 \%(1)$ & $50 \%(2)$ & $0 \%$ & $50 \%(2)$ \\
\hline Artesanato & $0 \%$ & $0 \%$ & $100 \%(1)$ & $33 \%(1)$ & $0 \%$ & $67 \%(2)$ \\
\hline
\end{tabular}

Fonte: Dados da pesquisa, 2020.

Ainda que com mais dificuldades para se manterem no emprego durante a pandemia, somente mulheres conseguiram emprego em meio à pandemia. Das três, uma trabalha sem serviço técnico de administração, outra como cuidadora de crianças, jovens, adultos e idosos e outra como operadoras do comércio em lojas e mercados. Observe-se que essas duas últimas têm estreita relação com a atual conjuntura, com alta demanda para cuidadores devido ao isolamento social e o aumento das vendas de supermercados face o fechamento de diversos outros estabelecimentos concorrentes. Todas as três foram inseridas em relações trabalhistas formais, uma com contrato temporário e as outras duas com carteira assinada. 
Quando perguntado aos 18 homens e 13 mulheres que estão empregados como a pandemia pode impactar em seus trabalhos, a maior parte respondeu que podem ser demitidos, sobretudo os homens, e que pode haver redução em seus salários, principalmente as mulheres (figura 3A). Também é considerável o número de homens e mulheres que não sabem como a pandemia pode afetar o seu trabalho, reforçando o momento de incerteza que atravessamos. Houve também uma mulher que afirmou que os seus serviços deixaram de ter procura devido às restrições impostas. Já em relação à mudança na dinâmica laboral, muitos homens preferiram não responder (figura 3B). Entre as mulheres percebe-se que pouco mais da metade está realizando o trabalho remotamente, diferentemente do restante que mantém a rotina laboral de antes da pandemia, mesmo padrão observado entre os homens que responderam à pergunta. Nesses casos, observa-se que a possibilidade de realização de trabalho remoto entre as mulheres e a distribuição de algumas delas em setores que não foram fechados devidos as medidas restritivas impediram um maior aumento do desemprego.

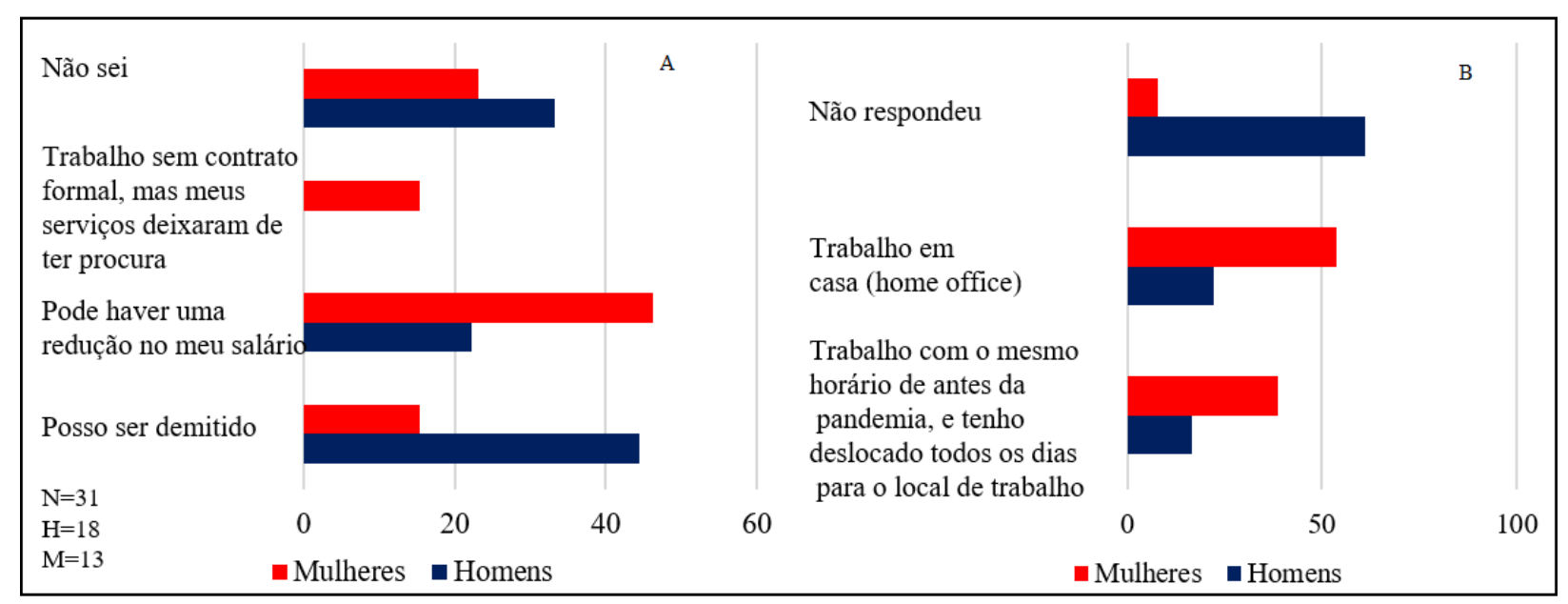

Figura 3 - Percepção de como a crise da pandemia de Covid-19 pode afetar o emprego (A) e alterações no trabalho/ocupação em função do distanciamento social na pandemia (B) entre imigrantes internacionais empregados. Região Metropolitana de Belo Horizonte, 2020.

Fonte: Dados da pesquisa, 2020.

Impactados por altos índices de desemprego, os imigrantes apontam para a insuficiência de sua renda para cobrir os seus gastos no Brasil. Dos 96 imigrantes, maiores de 16 anos, 66,5\% declararam que seus rendimentos não cobrem suas despesas, sendo que $35 \%$ afirmou que os rendimentos são muito menores que os gastos (figura 4A). Apenas $11 \%$ afirmaram que o rendimento é maior que seu gasto. Entre os gêneros observa-se maior vulnerabilidade entre as mulheres, ainda que pequena. Aproximadamente $65,3 \%$ destas não conseguem cobrir seus gastos, sendo que $37 \%$ afirmam ter renda muito inferior aos seus gastos. Entre homens os números são de $62 \%$ e $30 \%$ respectivamente.

Ainda que a maior parte não tenha rendimento suficiente para cobrir seus gastos, muitos afirmam enviar remessas de dinheiro para seu país de origem (figura 4B). A baixa renda no país de 
destino e a necessidade de envio de remessas ao país de origem indica que as dificuldades que grande parte desses indivíduos atravessavam em seu país de origem, continuam a se manifestar no seu destino. Observa-se que, proporcionalmente, mais mulheres enviam remessas do que homens, ainda que seja menor a proporção de mulheres com filhos fora do Brasil. Também é maior o número de mulheres dentre os que perderam o emprego durante a pandemia e enviam remessas ao país de origem. Nesse cenário são 7 das 12 mulheres e apenas 3 dos 10 homens. Dessa forma, além do desemprego impactar mais as mulheres, as suas repercussões podem ser mais graves para seus dependentes fora do país.

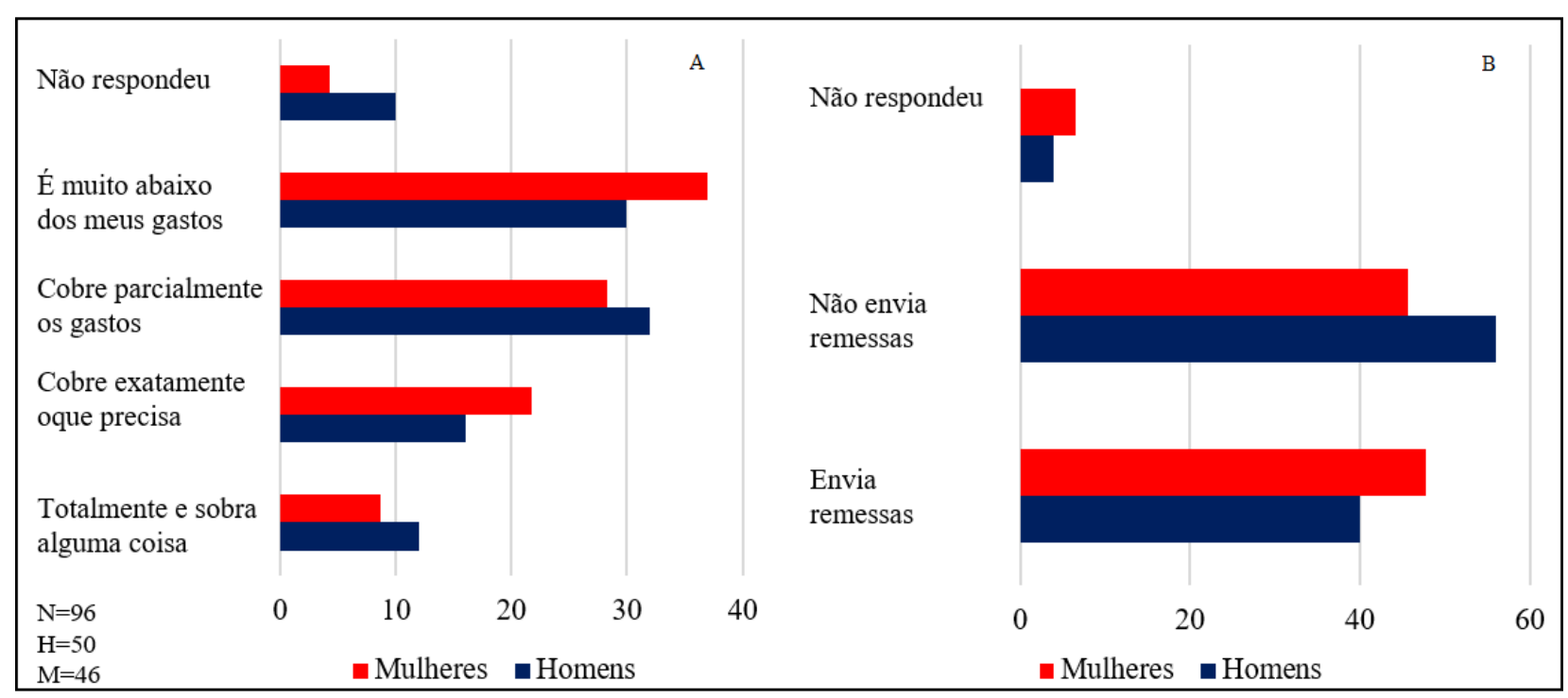

Figura 4 - Imigrantes internacionais participantes da pesquisa em idade laboral segundo percepção do rendimento (A) e envio de remessas (B) por gênero. Região Metropolitana de Belo Horizonte, 2020.

Fonte: Dados da pesquisa, 2020.

De forma geral, observa-se a partir dos resultados expostos na tabela 11 que as mulheres são mais cientes dos seus direitos sociais. Ainda que não busquem significativamente mais órgãos públicos ou da sociedade civil para coletar informações, as mulheres estão mais inscritas em programas do governo federal, no CadÚnico e no auxílio emergencial do que os homens.

Embora menos afetados pelo desemprego, não parece ser esse o motivo pelo qual há menos homens cadastrados para o auxílio emergencial. Dentre os 29 homens e 21 mulheres que não se inscreveram para o auxílio emergencial, cerca de $48 \%$ de cada gênero não o fizeram pois não fazem parte do grupo que pode ter acesso ao benefício. Entre os homens 3,4\% alegaram não terem conseguido se inscrever pelo site ou telefone, ainda que tenham tentado, e mais de $27,6 \%$ indicaram como empecilho a necessidade de ajuda e o não encontro de quem os auxilie. Entre as mulheres essas proporções são de $14,3 \%$ e $23,8 \%$. Mais de $20 \%$ dos homens e $14 \%$ das mulheres não quiseram responder essa questão. Devido ao alto índice de não resposta entre os homens, não é possível afirmar 
se os homens estão menos inscritos por falta de informação ou acesso a meios ou por não fazerem parte do grupo de acesso ao benefício.

Tabela 11: Imigrantes internacionais participantes da pesquisa segundo conhecimento dos direitos sociais (assistência social, saúde, educação) como imigrante no momento da pandemia por gênero. Região Metropolitana de Belo Horizonte, 2020 (número de respostas entre parênteses; $n=99 ; \mathrm{h}=51, \mathrm{~m}=48$ ).

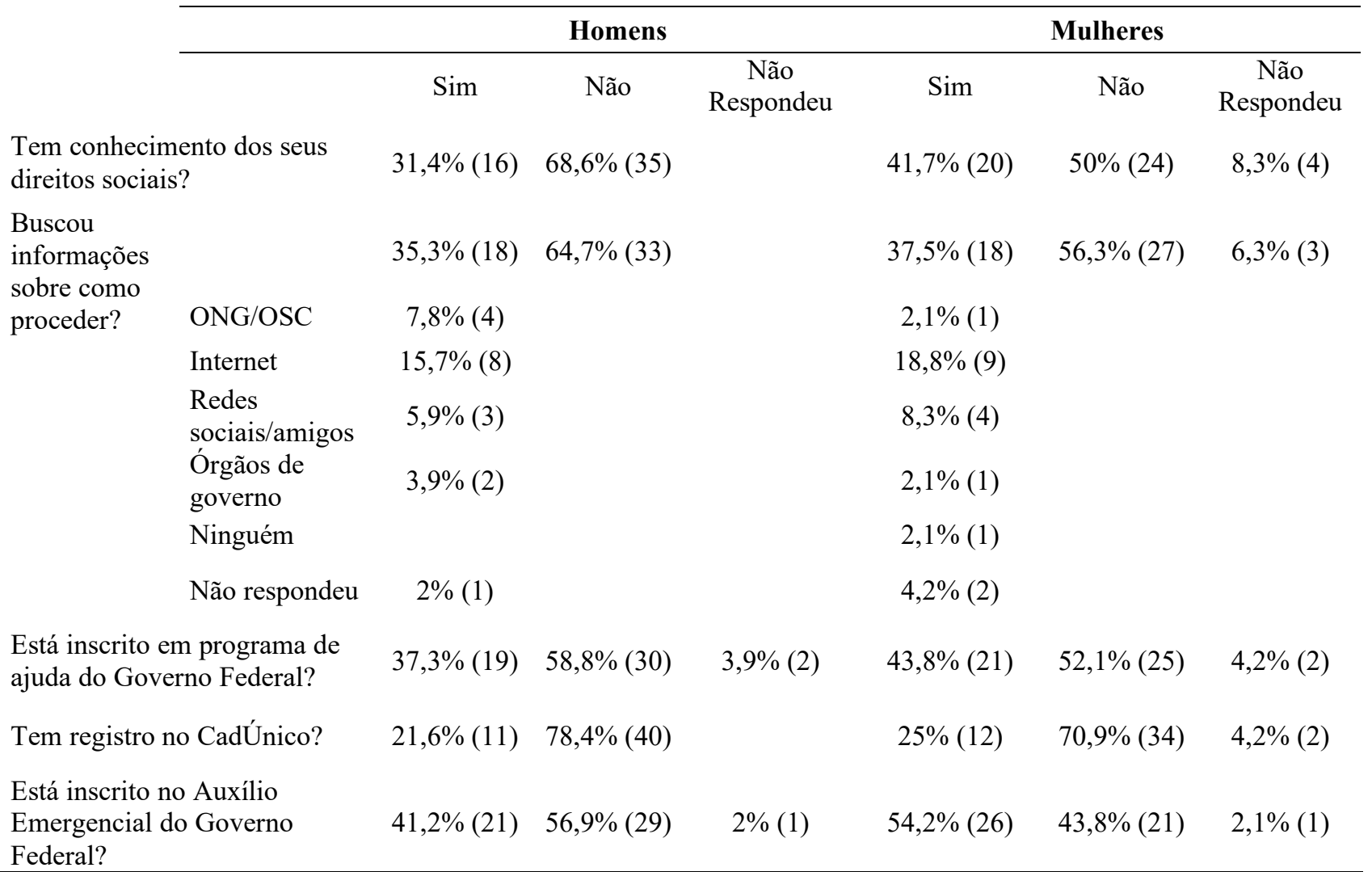

Fonte: Dados da pesquisa, 2020.

Quanto ao acesso dos imigrantes entrevistados ao Sistema Único de Saúde observa-se que mais de $73 \%$ possuem o Cartão do SUS. O índice é maior entre as mulheres $(81,3 \%)$ do que entre os homens (66,7\%). Pode-se entender a menor participação de homens entre os que possuem o cartão do SUS pelo seu menor conhecimento de direitos sociais e pelo fato de homens, de forma geral, buscarem menos auxílio de saúde. Entretanto, em tempos de pandemia, essa desinformação e postura podem ser perigosas. Tanto o é que o único homem que pegou Covid-19 ou teve algum parente contaminado não possui o cartão SUS e não buscou ajuda médica. Essa atitude pode contribuir para disseminação da doença na família e na comunidade e, em casos severos, tirar a vida de alguém. Já as duas mulheres que tiveram a doença em si ou na família possuíam o cartão SUS e, ao buscarem ajuda médica, receberam atendimento ambulatorial, onde foram aconselhadas a ficarem em isolamento domiciliar.

Desafio para todos nesse momento de pandemia, as restrições impostas pelo isolamento social são sentidas de diferentes formas pelas pessoas. Dentre os homens, 27,4\% afirmaram estar 
sendo fácil lidar com as restrições: 17,6\% acham relativamente fácil e 9,8\% muito fácil (figura 5). Os homens que estão achando relativamente difícil são 43,1\% e muito difícil 19,6\%. Esses números indicam que as mulheres que responderam à pesquisa estão sendo mais resilientes e adaptativas ao momento. Apesar de terem apresentado maiores dificuldades no campo laboral, há maior facilidade de elas lidarem com o momento adverso: $27,1 \%$ apontaram estar sendo relativamente fácil e 20,8\% muito fácil, totalizando $43,7 \%$ aquelas que não apresentam dificuldades com o isolamento social.

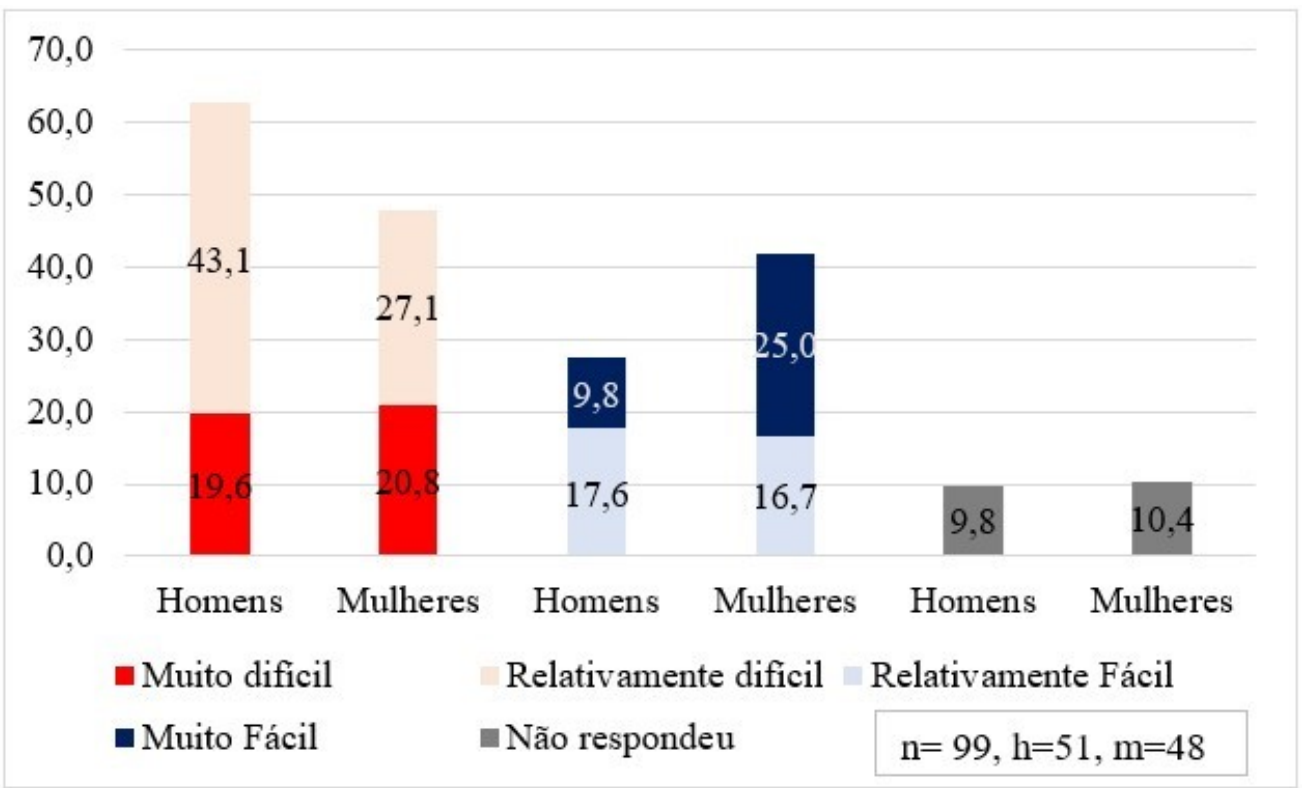

Figura 5 - Imigrantes internacionais participantes da pesquisa segundo avaliação do grau de dificuldade em lidar com as restrições impostas pelo isolamento social por gênero. Região Metropolitana de Belo Horizonte, 2020.

Fonte: Dados da pesquisa, 2020.

Dentre os dois grandes grupos de nacionalidade de imigrantes, haitianos e venezuelanos, os venezuelanos buscaram mais ajuda em organizações que trabalham em apoio aos imigrantes, tanto entre homens quanto entre mulheres: $80 \%$ dos homens venezuelanos ante $12,5 \%$ dos haitianos e $77 \%$ das mulheres venezuelanas frente $33 \%$ das haitianas. Além disso, todos haitianos homens que buscaram esse apoio possuem visto humanitário (50\% do total de homens haitianos com esse tipo de visto). Ressalta-se que a nacionalidade venezuelana é a mais comum entre as mulheres, enquanto entre homens é a haitiana. Dessa forma, as mulheres têm buscado mais ajuda em organizações que trabalham em apoio aos imigrantes. Ao todo, 33\% delas o fizeram, contra 21,6\% dos homens. Para ambos os gêneros a principal ajuda obtida é cesta básica. Um homem e uma mulher puderam contar com a ajuda financeira. Já ajuda psicológica/emocional e de saúde somente foram buscadas por mulheres.

Quando indicado para responderem a quem mais recorriam se precisassem de ajuda antes e depois do início da pandemia, observou-se que grande parte dos imigrantes homens e mulheres recorriam a parentes no país de origem e amigos e conhecidos brasileiros (figura 6). Entre homens, a 
participação de familiares no país de origem para ajuda caso necessário diminuiu após o início da pandemia, o que pode estar relacionado às dificuldades econômicas globais. Além disso, há menos homens pedindo ajuda para suas instituições de ensino, haja vista o não funcionamento de diversas delas. Dessa forma, entre os homens, aumentou-se a participação da ajuda dada por instituições religiosas e amigos brasileiros. Entre as mulheres, apesar da diferença no número de respostas dadas (43 antes da pandemia e 41 depois da pandemia), parece haver menor participação da ajuda de amigos brasileiros e maior apelo à religiosidade.

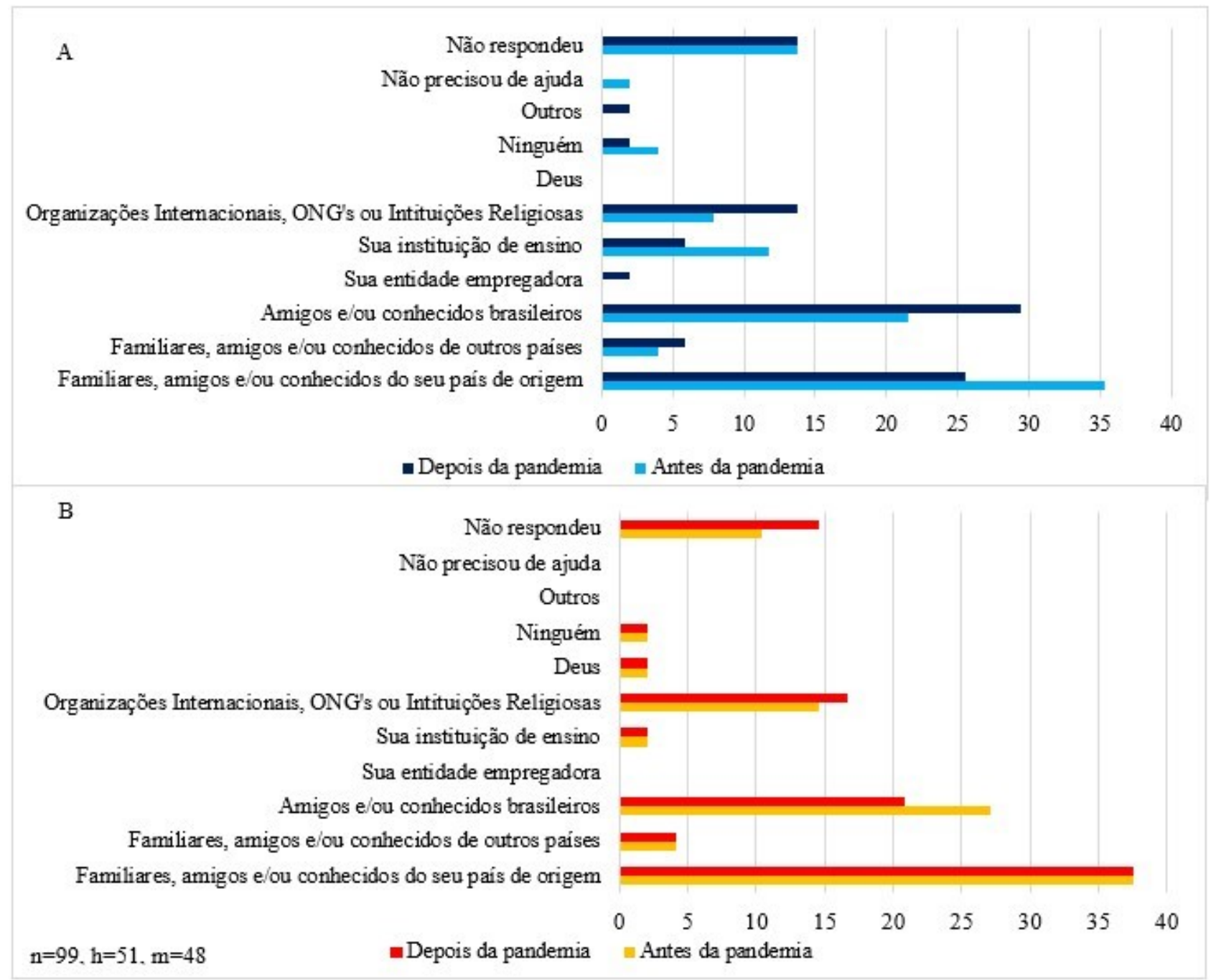

Figura 6 - Homens (A) e mulheres (B) imigrantes internacionais participantes da pesquisa segundo busca de ajuda antes e durante a pandemia. Região Metropolitana de Belo Horizonte, 2020.

Fonte: Dados da pesquisa, 2020.

Quando perguntado quais medidas foram tomadas em função da nova realidade que lhes fora imposta, a mais citada tanto por homens (47\%) como por de mulheres $(71 \%)$ foi a redução de despesas, sobretudo entre as mulheres (figura 7). Porém, salta aos olhos o alto número de relatos que está em situação que dificulta a própria sobrevivência: são $31 \%$ dos homens que responderam a esta questão e $26 \%$ das mulheres. Este índice é particularmente alto entre homens e mulheres haitianos 
(mais de 70\% de ambos), homens ganenses (100\%) e mulheres peruanas (100\%). Entre as mulheres é maior, porém, o endividamento para atravessar as adversidades financeiras causadas pela crise do SarsCov2. Outras medidas como distanciamento social, busca de fontes alternativas de renda e uso de reservas próprias ou de familiares também foram lembradas por um homem cada.

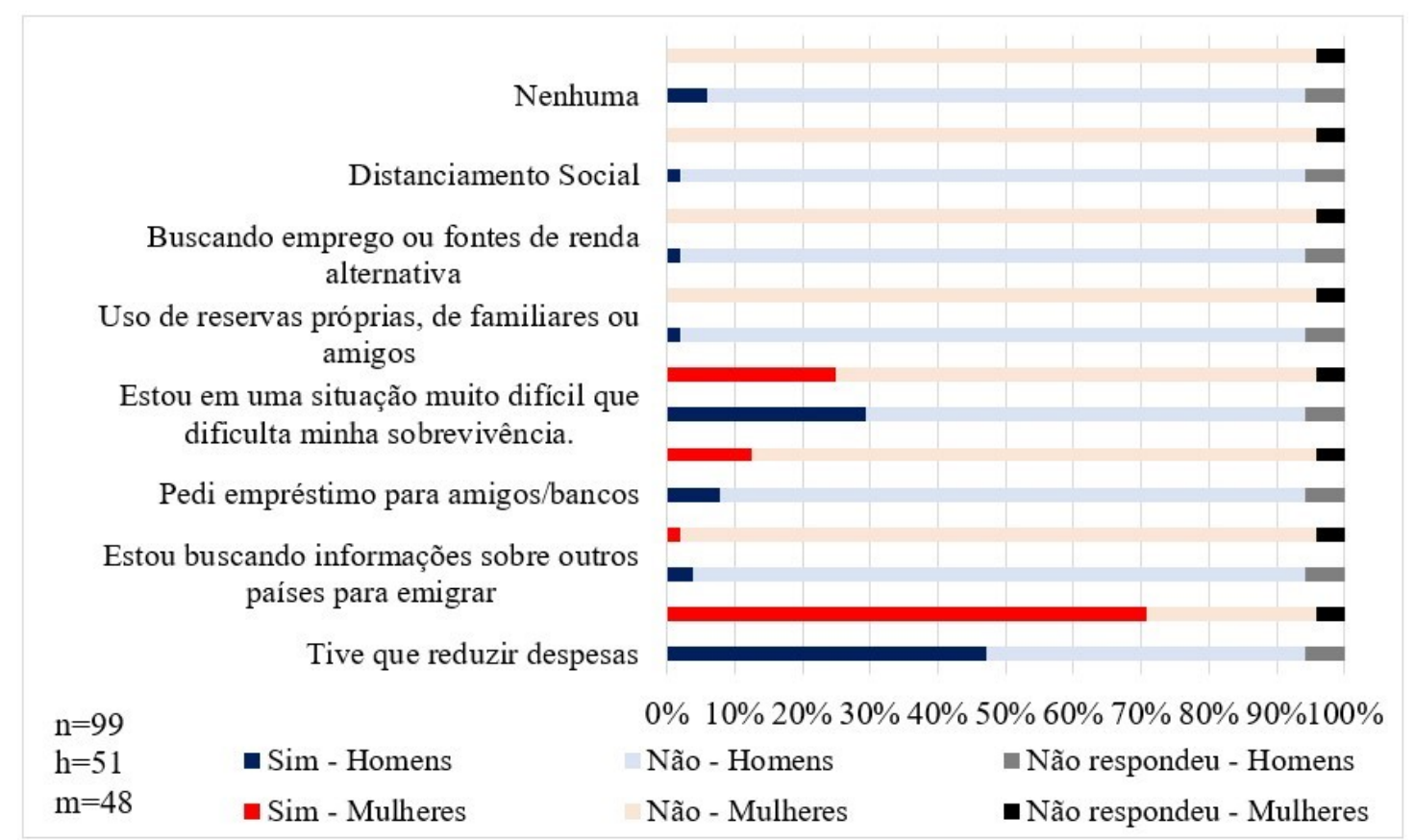

Figura 7 - Imigrantes internacionais participantes da pesquisa segundo medidas tomadas durante a pandemia por gênero. Região Metropolitana de Belo Horizonte, 2020

Fonte: Dados da pesquisa, 2020.

Diante de um cenário incerto no contexto pós-pandemia, foi perguntado aos imigrantes medos e preocupações que os afligem em decorrência da grave crise econômica e de saúde pública vivenciada. Nesse sentido, 76\% dos respondentes apontaram preocupações de cunho econômicolaborais, tais como ficar desempregado, não conseguir pagar o aluguel ou se submeter a trabalhos indesejados (tabela 12). Embora seja uma preocupação grande para ambos os gêneros, ela é maior e o principal medo das mulheres. Para $71 \%$ dos respondentes a saúde ou segurança alimentar são motivos de preocupação, seja pela falta de comida que já assola alguns, seja pelo medo de adoecer (ou algum ente próximo) e não ter acesso ao sistema de saúde. Também alta para ambos os gêneros, essa é a maior causa de medo entre os homens, sendo a segunda principal causa entre as mulheres. A terceira maior causa de preocupação para ambos os gêneros é a discriminação, uma vez que consideram que a xenofobia e/ou o racismo podem aumentar. Já a destruição de laços sociais foi a quarta mais apontada fonte de preocupação e medo, sobretudo pelos homens, que temem perder laços de amizades no período de pandemia, não conseguirem vagas nas escolas para os filhos, o aumento da desigualdade e até mesmo uma possível saída do país. Os aspectos legais, como a perda de direitos sociais e trabalhistas ou problemas com a documentação foram apontados como fonte de inquietação 
por 12 e $13 \%$ dos homens e mulheres respondentes, respectivamente. Ressalta-se que, dentre os pesquisados, apesar de mais homens terem deixado de responder a essa questão, os homens indicaram, proporcionalmente, mais preocupações que as mulheres.

Tabela 12: Imigrantes internacionais participantes da pesquisa segundo percepção do futuro por gênero. Região Metropolitana de Belo Horizonte, 2020. $(n=99, \mathrm{~h}=51, \mathrm{~m}=48)$.

\begin{tabular}{lccc}
\hline Principais preocupações/medos em relação ao futuro como imigrante & Homens & Mulheres & Total \\
\hline Econômico/Trabalho & $67 \%(34)$ & $85 \%(41)$ & $76 \%(75)$ \\
Discriminação & $51 \%(26)$ & $44 \%(21)$ & $47 \%(47)$ \\
Aspectos Legais & $12 \%(6)$ & $13 \%(6)$ & $12 \%(12)$ \\
Saúde e Segurança Alimentar & $76 \%(39)$ & $67 \%(32)$ & $71 \%(71)$ \\
Destruição de Laços Sociais & $25 \%(13)$ & $15 \%(7)$ & $20 \%(20)$ \\
Outros & $2 \%(1)$ & 0 & $1 \%(1)$ \\
Não respondeu & $8 \%(4)$ & $4 \%(2)$ & $6 \%(6)$ \\
\hline
\end{tabular}

Fonte: Dados da pesquisa, 2020.

Apesar de todas dificuldades para se inserirem no mercado de trabalho e dos temores frente a incerteza do cenário pós-pandemia, a maior parte dos imigrantes residentes na RMBH entrevistados nessa pesquisa demonstram vontade de permanecer no Brasil. Foi isso que cerca de $71 \%$ dos participantes da pesquisa afirmaram ao serem indagados sobre seus planos migratórios (figura 8). Embora proporcionalmente mais mulheres queiram ficar no Brasil, elas também são maioria entre os que gostariam de regressar ao país de origem. Contudo, o maior número de homens que não respondeu a essa questão pode estar influenciando esse resultado. Já entre os que desejam migrar para outro país é similar entre os dois gêneros.

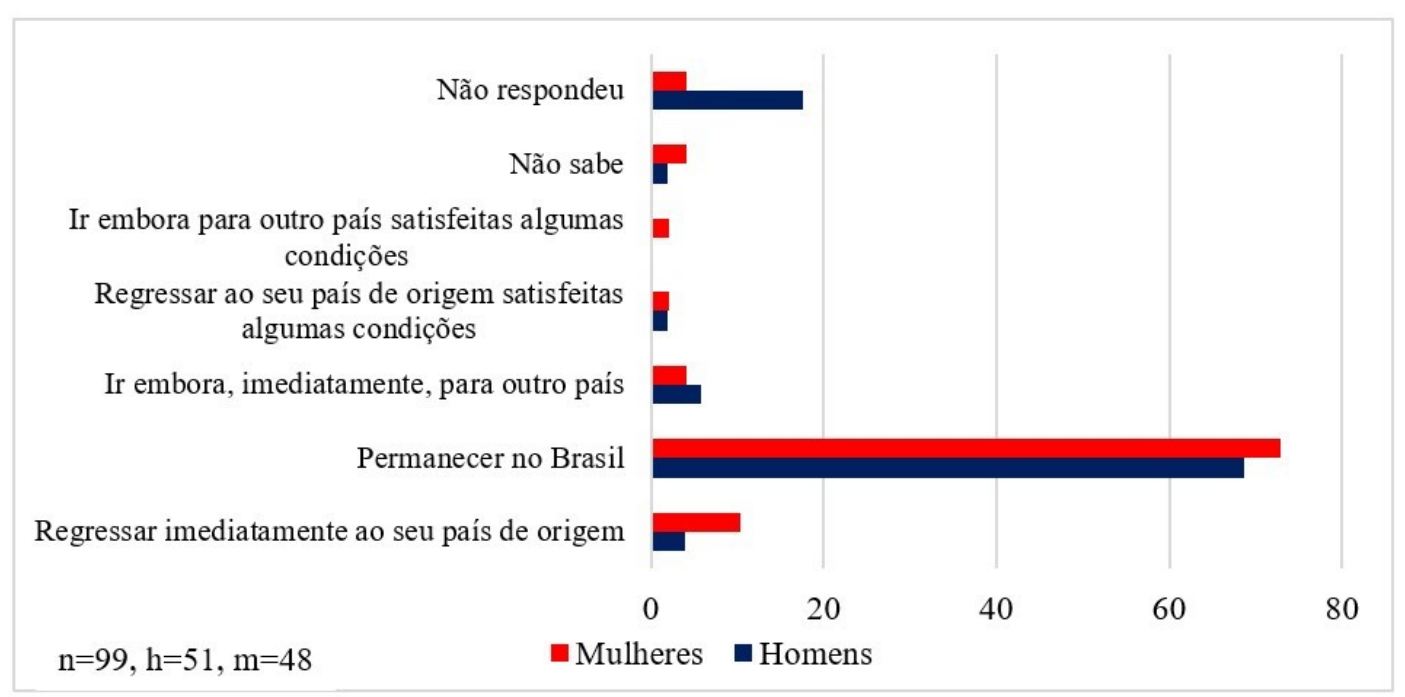

Figura 8 - Imigrantes internacionais participantes da pesquisa segundo planos migratórios por gênero. Região Metropolitana de Belo Horizonte, 2020.

Fonte: Dados da pesquisa, 2020. 


\section{CONSIDERAÇÕES FINAIS}

Embora os resultados da pesquisa não possam ser generalizados para toda a população de imigrantes, eles revelam, dentre os que responderam ao questionário, que a pandemia provocou fortes impactos no bem estar da comunidade imigrante da RMBH. Apesar do arranjo domiciliar dos imigrantes ser, no mais das vezes, facilitador da realização do isolamento social junto de sua família, não é possível afirmar que as condições sanitárias sejam adequadas e tampouco que haja como isolar um membro da família em caso de infecção. Há ainda imigrantes que vivem com outras pessoas, seja em casa ou em quarto compartilhado, o que dificulta o cumprimento do isolamento. Além disso, a grande maioria dos imigrantes vive em locais alugados ou cedidos por empregadores, o que pode levar a perderem sua condição de moradia caso percam o emprego ou haja forte redução em suas rendas.

Desde antes da pandemia era alta a taxa de desemprego entre os imigrantes, o que foi fortemente agravado pela crise econômica instalada com a pandemia. Se as mulheres tinham maiores dificuldades de se inserirem no mercado de trabalho antes da pandemia, também houve maior dificuldade para elas manterem seus empregos após o início da crise. Ainda que a distribuição mais concentrada em áreas afetadas pela pandemia e a maior informalidade de suas atividades expliquem parte dessa dificuldade, observou-se que em setores mais representativos as mulheres perderam mais seus empregos que os homens, mesmo que em condições trabalhistas semelhantes. A possibilidade de trabalho remoto e o não fechamento de algumas atividades que empregam mulheres imigrantes impediu um cenário pior. Ainda assim, muitos imigrantes, homens e mulheres, não possuem rendimentos capazes de arcar com as despesas necessárias, o que é intensificado, sobretudo entre as mulheres, pela necessidade de envio de remessas ao país de origem.

Em condições econômicas mais adversas, a maioria das mulheres estão inscritas no auxílio emergencial do governo federal, enquanto essa proporção entre homens é menor. Ainda que alguns homens e mulheres não estejam inscritos para o recebimento do auxílio por não fazerem parte do grupo que tem direito, observou-se que muitos não o estão por dificuldades diversas para acessá-lo. De toda forma, grande parte dos imigrantes, principalmente as mulheres, possuem mecanismos de acessar ao SUS, o que é extremamente importante em tempos de pandemia.

A maior parte das mulheres e grande parte dos homens reduziram as despesas como forma de superar as adversidades postas pela crise. Contudo, também chama a atenção a quantidade significativa de homens e mulheres que indicaram estar em situação que dificulta sua própria existência, indicando a deterioração das condições de vida dos imigrantes durante a pandemia.

Um ponto relevante no impacto diferencial da pandemia entre homens e mulheres imigrantes é a dificuldade que eles têm encontrado com as restrições impostas pelo período pandêmico. 
Conquanto mais afetadas do ponto de vista econômico, as mulheres têm achado mais fácil lidar com esse momento que os homens. Quanto às preocupações e medos, as mulheres destacam maiores temores em relação a questões econômicas, embora essa também seja uma preocupação relevante entre os homens. Já problemas relacionados a saúde e segurança alimentar são os que mais preocupam os homens, apesar deste número também ser alto entre as mulheres. Se por um lado são grandes as dificuldades e preocupações de homens e mulheres imigrantes na RMBH, a maior parte deles deseja ficar no país que os acolheu.

Sugerindo que o impacto da pandemia no mercado de trabalho foi mais forte entre as mulheres que entre os homens imigrantes, mas não necessariamente no campo social, esse trabalho possui algumas lacunas que podem ser supridas em outras pesquisas. A primeira delas é não ter analisado a influência da maternidade, da paternidade e da proximidade dos filhos no acesso ao mercado de trabalho. A segunda foi não ter sido possível controlar os efeitos que a nacionalidade (e toda conjuntura sociocultural que essa informação carrega consigo) dos imigrantes. Assim, estudos que foquem nos impactos diferenciais entre pais e mães e entre imigrantes de diferentes nacionalidades devem contribuir bastante para a identificação de subgrupos mais vulneráveis entre os imigrantes internacionais.

Por fim, salienta-se o papel cumprido pelas organizações internacionais e das organizações da sociedade civil nesse momento de crise. Como revelou os dados dessa pesquisa, o número de imigrantes que buscam essas organizações aumentou durante a pandemia, visto às dificuldades que atingem familiares e amigos dos imigrantes que antes os auxiliavam quando necessário. Contudo, é possível que essas fiquem sobrecarregadas, tornando ainda mais necessária a atuação de órgãos governamentais na assistência aos imigrantes, sejam eles homens, mulheres ou não-binários.

\section{AGRADECIMENTOS}

À CAPES pela concessão de bolsa de pesquisa de doutorado, que auxiliou na disponibilidade de um dos autores na realização dessa pesquisa.

\section{REFERÊNCIAS}

ADAMS-PRASSL, A.; BONEVA. T.; GOLIN, M.; RAUH, C. Inequality in the Impact of the Coronavirus Shock: Evidence from Real Time Surveys. IZA: Institute of Labor Economics, n. 13183, p. 1-49, 2020.

ALON, T.; DOEPKE, M.; OLMSTEAD-RUMSEY, J.; TERTILT, M. The impact of COVID-19 on gender equality. NBER Working Paper Series, Cambridge, n. 26947, p. 1-37, 2020.

ANDREW, A.; CATTAN, S.; DIAS, M. C.; FARQUHARSON, C.; KRAFTMAN, L.; KRUTIKOVA, S.; PHIMISTER, A.; SEVILLA, A. How are mothers and fathers balancing work and 
family under lockdown? The Institute for Fiscal Studies Briefing Note, Londres, n. 290, p. 1-30, 2020.

BAENINGER, R.; FERNANDES, D. M. Aspectos Metodológicos da Pesquisa "Impactos da Pandemia de Covid-19 nas Migrações Internacionais No Brasil”. In: FERNANDES, D. M.; BAENINGER, R.; CASTRO, M. C.; BALIEIRO, H. G.; ROCHA, J.; BORGES, F. Á. C. ; MAGAlHAES, L. F. A.; DEMETRIO, N. B.; DOMENICONI, J. O. S. Impactos da Pandemia de Covid-19 nas Migrações Internacionais no Brasil - Resultados de Pesquisa. Campinas: NEPO/UNICAMP, 2020. p. 13-19.

BRASIL. Ministério da Justiça, Ministério da Segurança Pública, Ministério das Relações Exteriores, Ministério do Trabalho. Portaria Interministerial $\mathbf{n}^{\mathbf{0}}$ 10, de 6 de abril de 2018. Brasília, 2018. Disponível em: https://www.in.gov.br. Acesso em: 15 set. 2020.

BRASIL. Ministério da Justiça e da Segurança Pública, Ministério das Relações Exteriores. Portaria Interministerial $\mathbf{n}^{\mathbf{0}}$ 12, de 20 de dezembro de 2019. Brasília, 2019. Disponível em: http://www.pf.gov.br/servicos-pf/imigracao/cedula-de-identidade-de-estrangeiro. Acesso em: 15 set. 2020.

BRÜLHART, M.; LALIVE, R. Daily suffering: Helpline calls during the Covid-19 crisis. Covid Economics, Vetted and Real-Time Papers, Londres, v. 19, p. 143-158, 2020.

CLARK E.; FREDRICKS K.; WOC-COLBURN L.; BOTTAZZI M. E.; WEATHERHEAD J. Disproportionate impact of the COVID-19 pandemic on immigrant communities in the United States. PLoS Negl Trop Dis, São Francisco, v. 14, n. 7, p. 1-9, 2020.

COLLINS C.; LANDIVAR, L. C.; RUPPANNER L.; SCARBOROUGH, W. J. COVID-19 and the gender gap in work hours. Gender, Work \& Organization, Nova Iorque, p. 1-12, 2020.

ETHERIDGE, B.; SPANTIG, L. The Gender Gap in Mental Well-Being During the Covid-19 Outbreak: Evidence from the UK. ISER Working Paper Series, n. 2020-08, p. 1-23, 2020.

FARRÉ, L.; FAWAZ, Y.; GONZÁLEZ, L.; GAVES, J. How the COVID-19 Lockdown Affected Gender Inequality in Paid and Unpaid Work in Spain. IZA Discussion Papers, n. 13434, p. 1-36, 2020 .

FERNANDES, D. M. ; BAENINGER, R.; CASTRO, M. C.; BALIEIRO, H. G.; ROCHA, J.; BORGES, F. Á. C. ; MAGAlhaES, L. F. A.; DEMETRIO, N. B.; DOMENiCONI, J. O. S. (Org.). Impactos da Pandemia de COVID-19 nas migrações internacionais no Brasil Resultados de pesquisa. 1. ed. Campinas: NEPO/UNICAMP, 2020. 686p.

FERNANDES, D.; BAENINGER, R.; DEMÉTRIO, N. B. Resultados da Pesquisa: Impactos da Pandemia de Covid-19 nas Migrações Internacionais no Brasil. In: FERNANDES, D. M.; BAENINGER, R.; CASTRO, M. C.; BALIEIRO, H. G.; ROCHA, J.; BORGES, F. Á. C.; MAGAlhaes, L. F. A.; DEMEtrio, N. B.; DOMENiCONI, J. O. S. Impactos da Pandemia de Covid-19 nas Migrações Internacionais no Brasil - Resultados de Pesquisa. Campinas: UNICAMP/NEPO, 2020. p. 35-79.

FERnANDES, D. M.; CASTRO, M. C.; BAlieiro, H. G.; ROCHA, J.; BORGES, F. Á. C. Imigrantes Internacionais no Estado de Minas Gerais. In: FERNANDES, D. M.; BAENINGER, R.; CASTRO, M. C.; BALIEIRO, H. G.; ROCHA, J.; BORGES, F. Á. C.; MAGAlHAES, L. F. A.; DEMETRIO, N. B.; DOMENICONI, J. O. S. 
Impactos da Pandemia de Covid-19 nas Migrações Internacionais no Brasil - Resultados de Pesquisa. Campinas: UNICAMP/NEPO, 2020. p. 288-315.

FERNANDES, D.; FARIA, A. V. O visto humanitário como resposta ao pedido de refúgio dos haitianos. Revista Brasileira de Estudos de População, v. 34, n. 1, p. 145-161, 2017.

GELATT, J. Immigrant Workers: Vital to the US COVID-19 Response, Disproportionately Vulnerable. Migration Policy Institute, Washington, p. 1 -14, abr. 2020.

KING, T.; HEWITT, B.; CRAMMOND, B.; SUTHERLAND, G.; MAHEEN, H.; KAVANAGH, A. Reordering gender systems: can COVID-19 lead to improved gender equality and health?. The Lancet, v. 396, n. 10244, p. 80-81, 2020.

KLUGE, H. H. P.; JAKAD, Z.; JOZEF, B.; D'ANNA, V.; SEVERONI, S. Refugee and migrant health in the COVID-19 response. The Lancet, Londres, v. 395, n. 10232, p. 1237-1239, 2020.

MALIK, R.; HAMM, K.; LEE, W. F.; DAVIS, E. E.; SOJOURNER, A. The coronavirus will make child care deserts worse and exacerbate inequality. Washington, DC: Center for American Progress. Disponível em: https://www.americanprogress.org/issues/early-childhood/reports. Acesso em: 12 set. 2020.

OIT. World employment and social outlook: trends 2019. Genebra: International Labour Organization, 2019. Disponível em: https://www.ilo.org/wcmsp5. Acesso em 24 set. 2020

OIT. ILO monitor: COVID-19 and the world of work, sixtth edition. Genebra: International Labour Organization, 2020. Disponível em https://www.ilo.org/wcmsp5/groups/public/---dgreports/--dcomm/documents/briefingnote/wcms_755910.pdf. Acesso em: 24 set. 2020.

OMS. WHO Coronavirus Disease (COVID-19) Dashboard. Genebra: Organização Mundial da Saúde, 2020. Disponível em https://covid19.who.int/?gclid=CjwKCAjww5r8BRB6EiwArcckC7wA3VIWNYXDTj3J1TIcL-rx1MoxPjaN0eVzIJXevorafGUx3F3ShoCvEUQAvD_BwE Acesso em: 24 set. 2020

ONU. The Impact of COVID-19 on Women. UN Policy Brief. Nova Iorque: Organização das Nações Unidas, 2020. Disponível em: https://www.un.org/sexualviolenceinconflict/wpcontent/uploads/2020/06/report/policy-brief-the-impact-of-covid-19-on-women/policy-brief-theimpact-of-covid-19-on-women-en-1.pdf Acesso em: 12 set. 2020.

Trabalho enviado em $16 / 08 / 2020$

Trabalho aceito em $21 / 10 / 20$ 